\title{
Environmental health hazard of arsenic on epididymis and ductus deferens in male Black Bengal Goats
}

\author{
M. A. Wares, M. A. Awal, M. Nasrin ${ }^{*}$ and M. N. H. Siddiqi \\ Department of Anatomy and Histology, Faculty of Veterinary Science, Bangladesh Agricultural University, \\ Mymensingh-2202, Bangladesh, *E-mail: mithundvm@yahoo.com
}

\begin{abstract}
Histomorphological changes of epididymis and ductus deferens in male Black Bengal goat due to arsenic were studied. A total of 12 male Black Bengal goats, in which 6 were collected from arsenic affected areas of Mymensingh district and another 6 were collected from hill tracts of Chittagong which were arsenic free.The goats were sacrificed by piercing carotid artery and the samples (Epididymis and Ductus deferens) were collected immediately. Samples were prepared and stained with haematoxylin and eosin stain technique to study the histology under light microscope. In the morphological study, measurement of length, width, breadth and weight of epididymis and ductus deferens were observed. The gross study revealed that there were slight variations in the gross morphology of epididymis and ductus deferens of arsenic affected Black Bengal goat, but this variation was statistically insignificant. In the histological study, arsenic affected goat showing increased thickness of epididymal covering $(P<0.05)$ and trabeculae compared to control group of epididymis. The diameter of ductule efferentes of arsenic affected goat was narrower $(P<0.01)$, width between intertubular space of ductuli efferentes was wider $(P<0.01)$, lumen of ductules contain smaller in amount of spermatozoa compared to control group. The wall of the ductus deferens was thicker in arsenic affected goats than the control group $(P<0.01)$. It may be concluded that environmental health hazard of arsenic might have adverse effects on the male reproductive organs.
\end{abstract}

Keywords: Arsenic, Morphology, Histology, Epididymis, Ductus Deferens, Black Bengal goat

\section{Introduction}

Arsenic poisoning from underground drinking water in Bangladesh was first identified in 1993 in the Nawabgonj district (Smith et al., 2000). Almost 57 of 140 million people (Mahmood, 2002) and 61 of total 64 districts of Bangladesh are reported to have dangerous levels of inorganic arsenic $(>50 \mu \mathrm{g} / \mathrm{L})$ in most of the tube wells (DPHE, BGS and MML, 1999; BAMWSP, 2001). Arsenic can enter into food chain (Ulman et al., 2004) causing wide spread distribution throughout the plant and animal kingdoms. Arsenic is present in milk and meat in Bangladesh (Awal, 2007). Organic arsenic exposure can occur by eating food. Inorganic arsenic trioxide is a component of geologic formations and can be washed out into the ground water (M. T. Islam et al., 2011). Chronic arsenic toxicity due to drinking of arsenic contaminated ground water is a major environmental health hazard throughout the world (Mazumder, 2008). WHO described the condition as "the largest mass poisoning of a population in history" (WHO, 2004). Acute arsenic exposure may promote immediate gastrointestinal tract infection (Goebl et al. 1990), whereas chronic effects may exert degenerative, inflammatory and neoplastic changes of respiratory, haematopoetic, cardiovascular and nervous systems (Neiger \& Osweiler 1989). The effects may include shortened life expectancy, decrease in reproduction, and behavioural changes. Arsenic is a recognized reproductive toxicant in humans and induces malformations. Recently arsenic intoxication in experimental animals has been found to be associated with hepatic tumors (Waalkes et al., 2003), inhibition of testicular steroidogenic function (Sarkar et al., 1991) and spermatogenesis (Sukla \& Pandey, 1984), as well as with severe metabolic disorders such as diabetes in humans (Longnecker \& Daniels, 2001, Tseng etal., 2002).

However, information related to effects of environmental health hazard of arsenic on the epididymis and ductus deferens of goat is yet to know. Therefore, the present study was conducted to observe the environmental health hazard of arsenic on epididymis and ductus deferens in Black Bengal goats. 


\section{Materials and Methods}

A total of 12 mature male Black Bengal goats were used in this study. Six goats were collected from arsenic affected areas of Mymensingh district and another six from arsenic free areas of hill tracts of Chittagong. The goats were sacrificed by piercing carotid artery and the samples (Epididymis and Ductus deferens) were collected immediately. Soon after collection of samples, gross parameters (Colour, length, width, breadth and weight) of epididymis and ductus deferens were observed and recorded. For histological studies, the samples were cut into small pieces and then fixed in the "Bouins fluid" (Gridley, 1960) for 18-24 hours and were dehydrated in the series of ascending grade of alcohol followed by clearing in three changes in xylene, and the tissues then infiltrated with different grades of melted paraffin in the oven (M. T. Islam et al., 2011). The tissues were then embedded in paraffin and finally the sections were cut at $6 \mu \mathrm{m}$ thickness using sliding microtome (MIC 509, Euromex, Japan). After cutting, the sections were floated on luke-warm water in a floatation bath at $37^{\circ} \mathrm{C}$ for stretching and then the sections were mounted on clean slides using an adhesive (Egg albumins) and dried on a slide warmer. The sections were stained using Mayer's Hematoxylin and Eosin (H \& E) stain. The stuctures were examined by using light microscope under low 10x, 20x and high 100x magnification. Measurements of structures were taken by the calibrated stage micrometer and photograph was taken for better illustration. The recorded data were compiled and tabulated for statistical analysis by the help of Computer package SPSS 11. The mean was compared in one-way ANOVA Method.

\section{Results and Discussion}

\section{Morphological effects of arsenic on epididymis}

The epididymis was closely attached along the caudal border of the testis. The head was long (Fig. 4) and curves over the dorsal extremity. The body was very narrow (Fig. 4) and lies along the lateral part of the caudal border of the testicle, to which it was attached by a narrow peritoneal fold. The tail was large and closely attached at the ventral extremity of the testicle (Fig. 4). Colour of the epididymis was pale white to yellowish white (Fig. 4). The weight of the epididymis of aresenic affected goat and control group of goats were $6.1 \pm 0.1 \mathrm{~g}$ and $6.5 \pm 0.0 \mathrm{~g}$, respectively (Fig. 1). Length of the epididymis of aresenic affected goat and control group of goats were $10.0 \pm 0.0 \mathrm{~cm}$ and $10.0 \pm 0.0 \mathrm{~cm}$, respectively (Fig. 1). Width and breadth of the epididymis of aresenic affected goat and control group of goats were taken from the body part. Calculated width was $0.5 \pm 0.0 \mathrm{~cm}$ from arsenic affected goat and $0.4 \pm 0.0 \mathrm{~cm}$ from control group of goat respectively (Fig. 1). Measured breadth was $1.6 \pm 0.0 \mathrm{~cm}$ and $1.7 \pm 0.0 \mathrm{~cm}$, respectively (Fig. 1). Through statistical analysis, it was observed that the difference of weight, length, breadth and width of epididymis between arsenic affected and control group of goats was insignificant (Fig. 1).

\section{Morphological effects of arsenic on ductus deferens}

The ductus deferens was small in caliber and had a much thinner wall (Fig. 4). First it pursued a flexuous course dorsally along the caudal border of the testicle, then became straight and lied in the caudal part of the spermatic cord.

The colour of the ductus deferens was yellowish white (Fig. 4). The weight of the ductus deferens of aresenic affected goat and control group of goats were $1.6 \pm 0.0 \mathrm{~g}$ and $1.7 \pm 0.0 \mathrm{~g}$, respectively (Fig. 2). Length of the ductus deferens of aresenic affected goat and control group of goats were $26.9 \pm 0.3 \mathrm{~cm}$ and $27.3 \pm 0.2 \mathrm{~cm}$, respectively (Fig. 2). Width of the ductus deferens of aresenic affected and control group of goats were $0.3 \pm 0.0 \mathrm{~cm}$ and $0.3 \pm 0.0 \mathrm{~cm}$, respectively (Fig. 2). The breadth of the ductus deferens of aresenic affected goat and control group of goats were $0.6 \pm 0.0 \mathrm{~cm} 0.6 \pm 0.0 \mathrm{~cm}$, respectively (Fig. 2). Though there are some variations in weight, length, breadth and width of ductus deferens between arsenic affected and control group of goats, but it was statistically insignificant (Fig. 2). 


\section{Histological effects of arsenic on epididymis}

Present study was performed to detect the effects of arsenic on epididymis. It was shown that there were more dense irregular connective tissue, collagen fiber and elastic fibers in covering of epididymis of arsenic affected goats than the control group of goats (Fig. 5a, 5c). Thickness of covering of epididymis of arsenic affected goat was $373.6 \pm 10.8 \mu \mathrm{m}$ (Fig. 3, 5a) whereas control group of goat had $290.4 \pm 15.3$ $\mu \mathrm{m}$ (Fig. 3, 5c). Fujihara et al. (2004), detected arsenic was in all analyzed tissues except bone in both sexes and muscles with connective tissue had the highest arsenic concentrations. This finding support present observations that reproductive tract showed thicker wall. This is may be due to the effect of arsenic which lead to more generation of connective tissue. Each duct of the epididymis was in normal arrangement and sequentially present in control group of goats. But, in arsenic affected goats the ductule were not arranged sequentially (Fig. 6a, 6c). Diameter of ductuli efferentes of arsenic affected goat was $879.4 \pm 18.6 \mu \mathrm{m}$ whereas control group of goat had diameter of ductuli efferentes was $1193.5 \pm 18.6 \mu \mathrm{m}$ (Fig. 3, 7a and 7c). The interlobular space between ductuli efferentes were wider in arsenic affected goats than the control group of goats (Fig. 6a, 6c). Width between interlobular space of ductuli efferentes of arsenic affected goat was $159.5 \pm 9.9 \mu \mathrm{m}$ (Fig. 3, 6a) whereas control group of goat had interlobular space of thickness $90.9 \pm 6.9 \mu \mathrm{m}$ (Fig. 3, 6c). The ductule of epididymis had clumping of spermatozoa in the center of lumen in the control group of goats which was clearly visible in higher magnification. But the arsenic affected goats had a very smaller number of spermatozoa in the lumen of ductules of epididymis (Fig. 7a, 7c). This finding is similar with Mahitosh-Sarkar et al. (2003), where he found that lowering epididymal sperm count and plasma concentrations of $\mathrm{LH}, \mathrm{FSH}$ and testosterone with massive degeneration of germ cells and arsenite has a suppressive influence on spermatogenesis and testosterone release in rats. Present study showed that decrease diameter of ductuli efferentes and increased area of intertubular space in arsenic affected goats compare to that of control group of goats. The difference between arsenic affected and control group was statistically significant $(P<0.01)$ in the thickness of covering $(\mu \mathrm{m})$, diameter of ductules $(\mu \mathrm{m})$ and thickness of interlobular space of epididymis $(\mu \mathrm{m})$ (Fig. 3).

\section{Histological effects of arsenic on ductus deferens}

The ductus deferens was the continuation of the ductus epididymidis, which gradually straightend out toward the end of the tail of the epididymis and acquired the characteristics of the ductus deferens. Present study showed that lamina propria and tunica submucosa had more loose connective tissue. The wall of the ductus deferens was thicker (Fig. 8a, 8c). Thickness of wall of ductus deferens of arsenic affected goat was $802.8 \pm 28.0 \mu \mathrm{m}$ whereas control group of goat had thickned wall of ductus deferens $563.3 \pm 14.5 \mu \mathrm{m}$ (Fig. 3, 8a, 8c). The difference in the thickness of wall of ductus deferens between arsenic affected and control group was statistically significant $(P<0.01)$ (Fig. 3). 


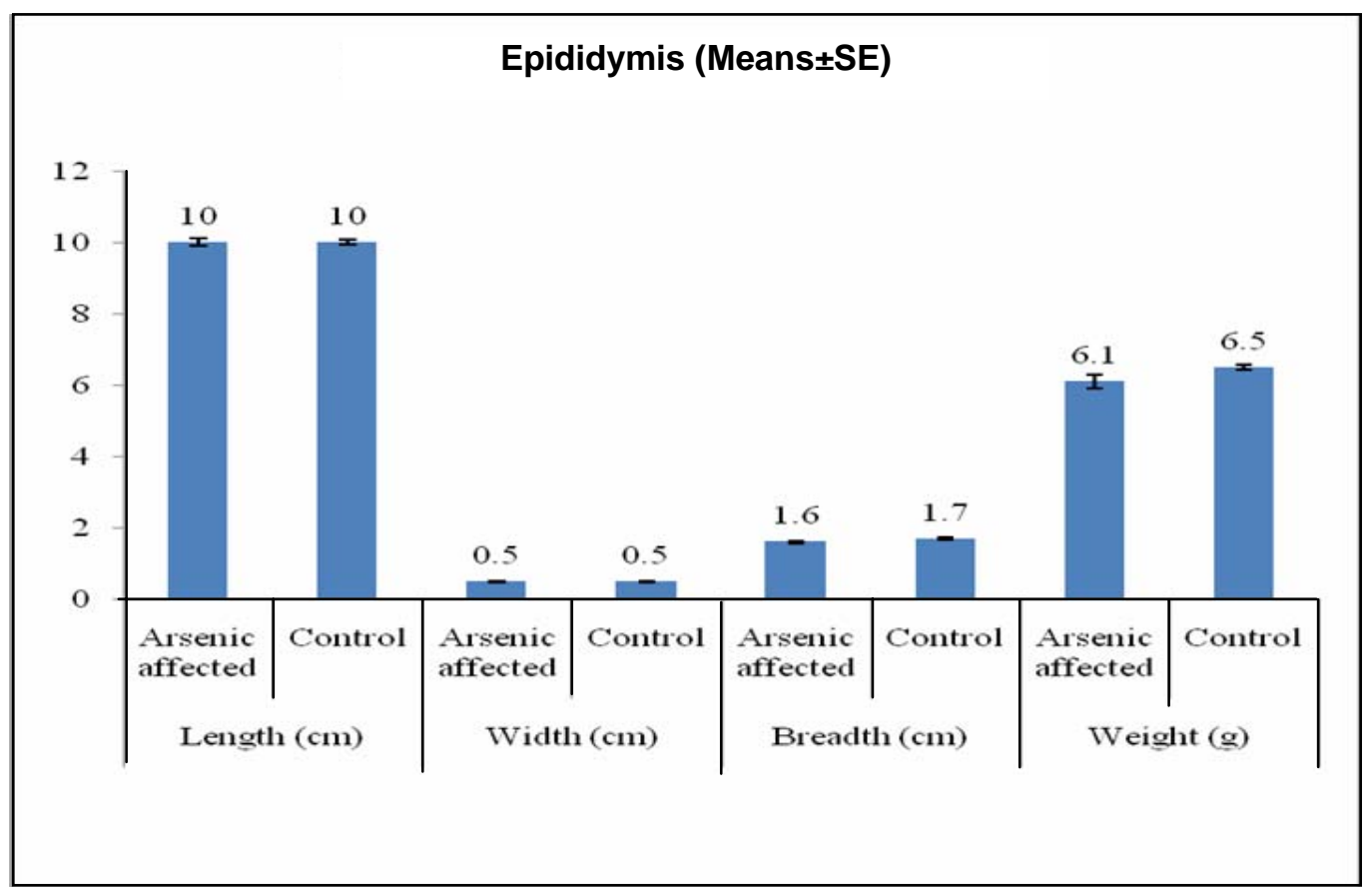

Fig. 1. Mean length, width, breadth and weight of epididymis between arsenic affected and control group of goats through 2-D column chart $(n=12)$

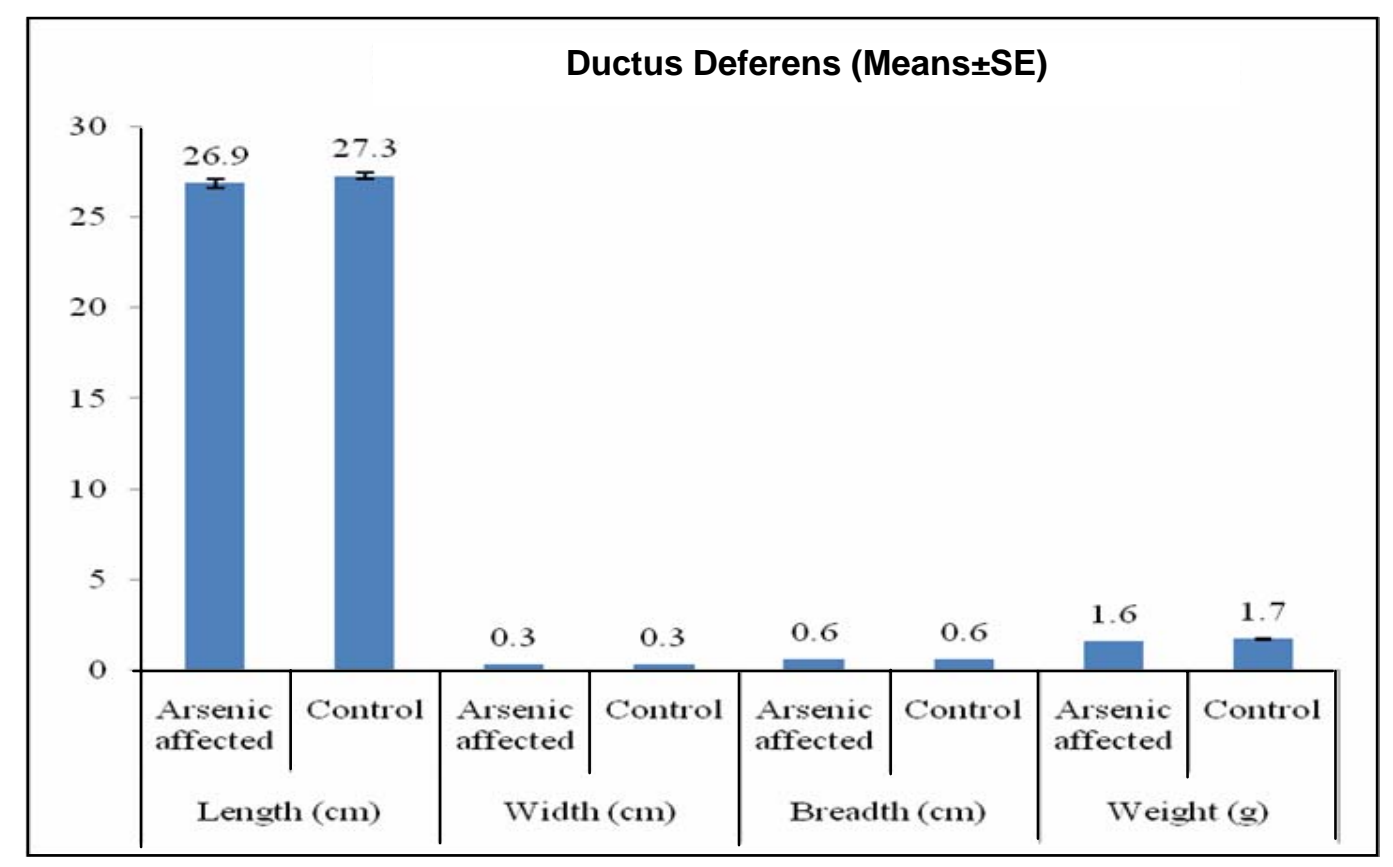

Fig. 2. Mean length, width, breadth and weight of ductus deferens between arsenic affected and control group of goats through 2-D column chart $(n=12)$ 


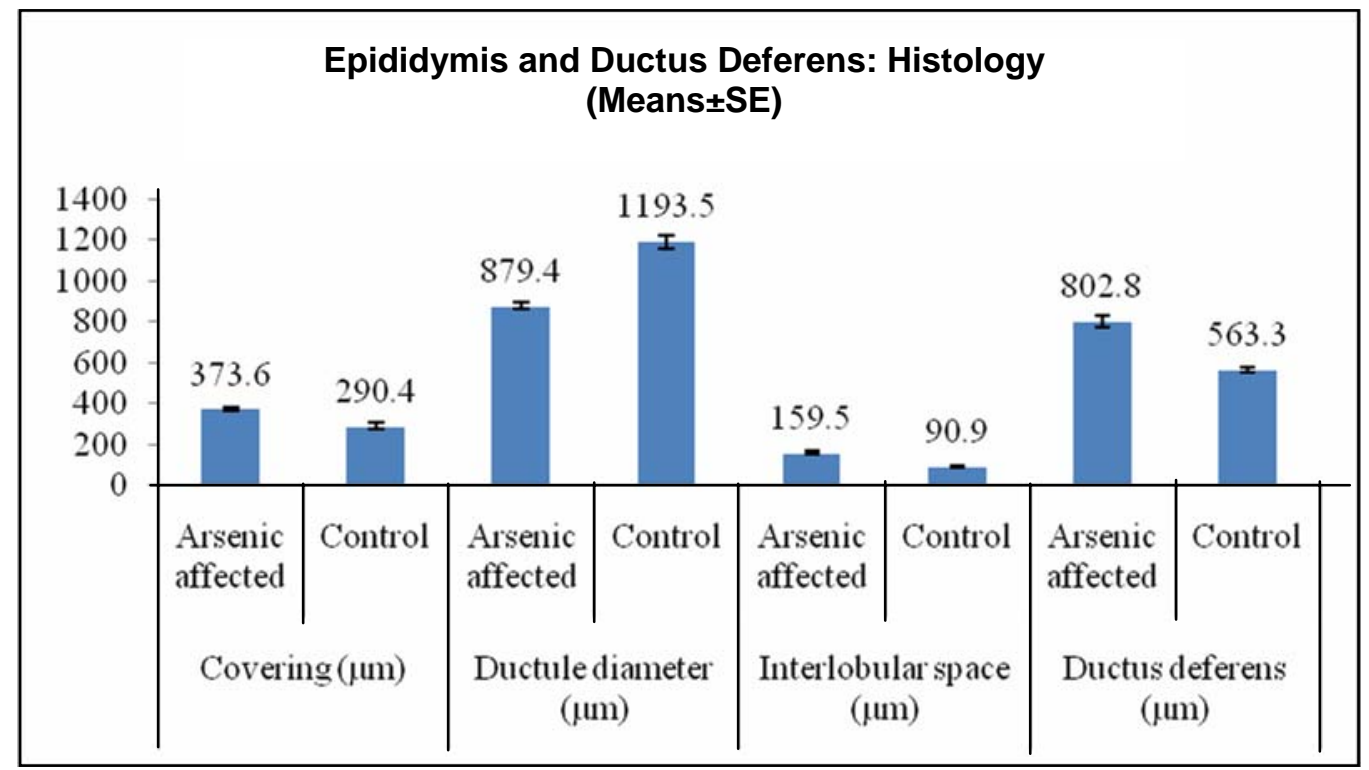

Fig. 3. Mean thickness of covering $(\mu \mathrm{m})$, diameter of ductules $(\mu \mathrm{m})$ and thickness of interlobular space $(\mu \mathrm{m})$ of epididymis and thickness of wall of ductus deferens $(\mu \mathrm{m})$ between arsenic affected and control group of goats through 2-D column chart $(n=12)$
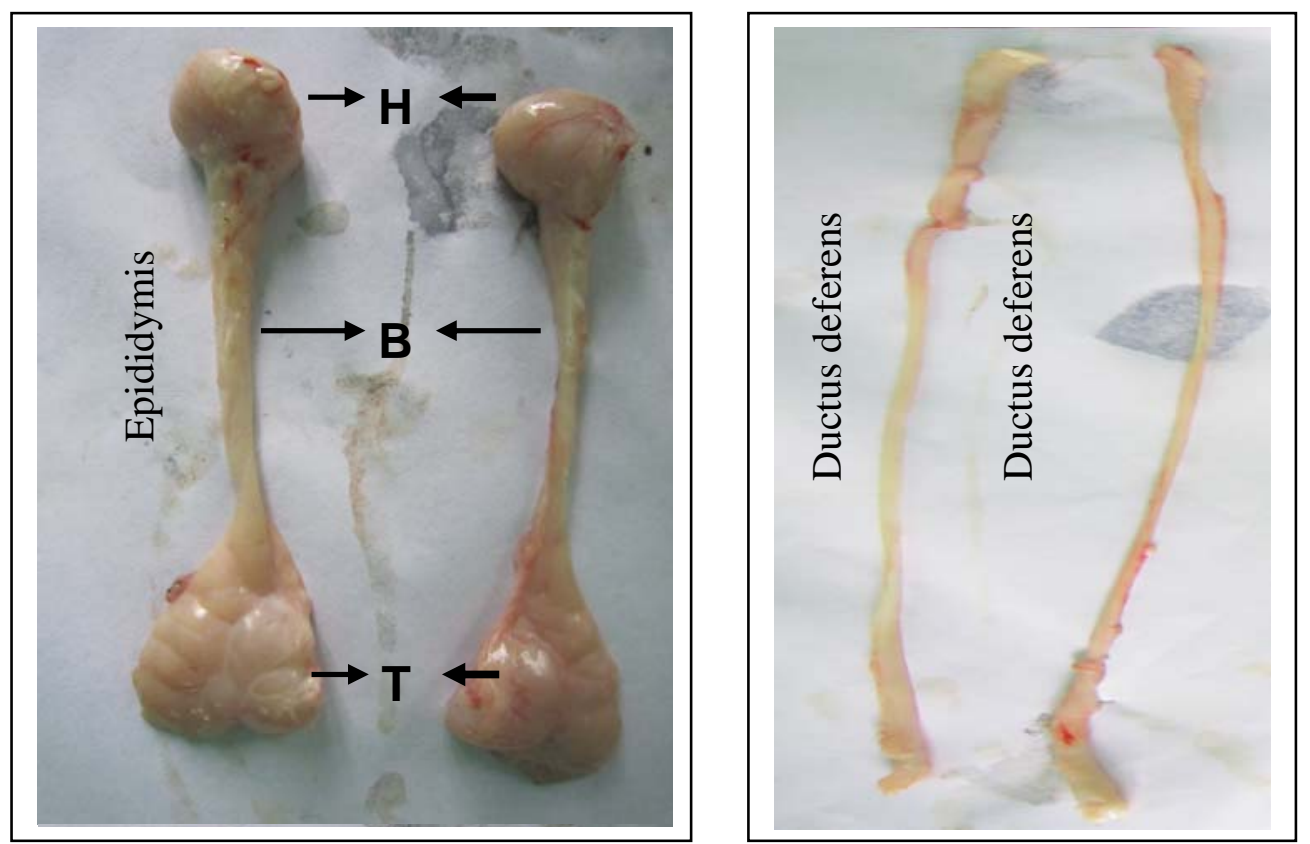

Fig. 4. There is no visible or gross lesions of arsenic on epididymis and ductus deferens. Figure shows epididymis (Left side ) and its different parts are Head (H), Body (B), Tail (T) and ductus deferens (Right side) 

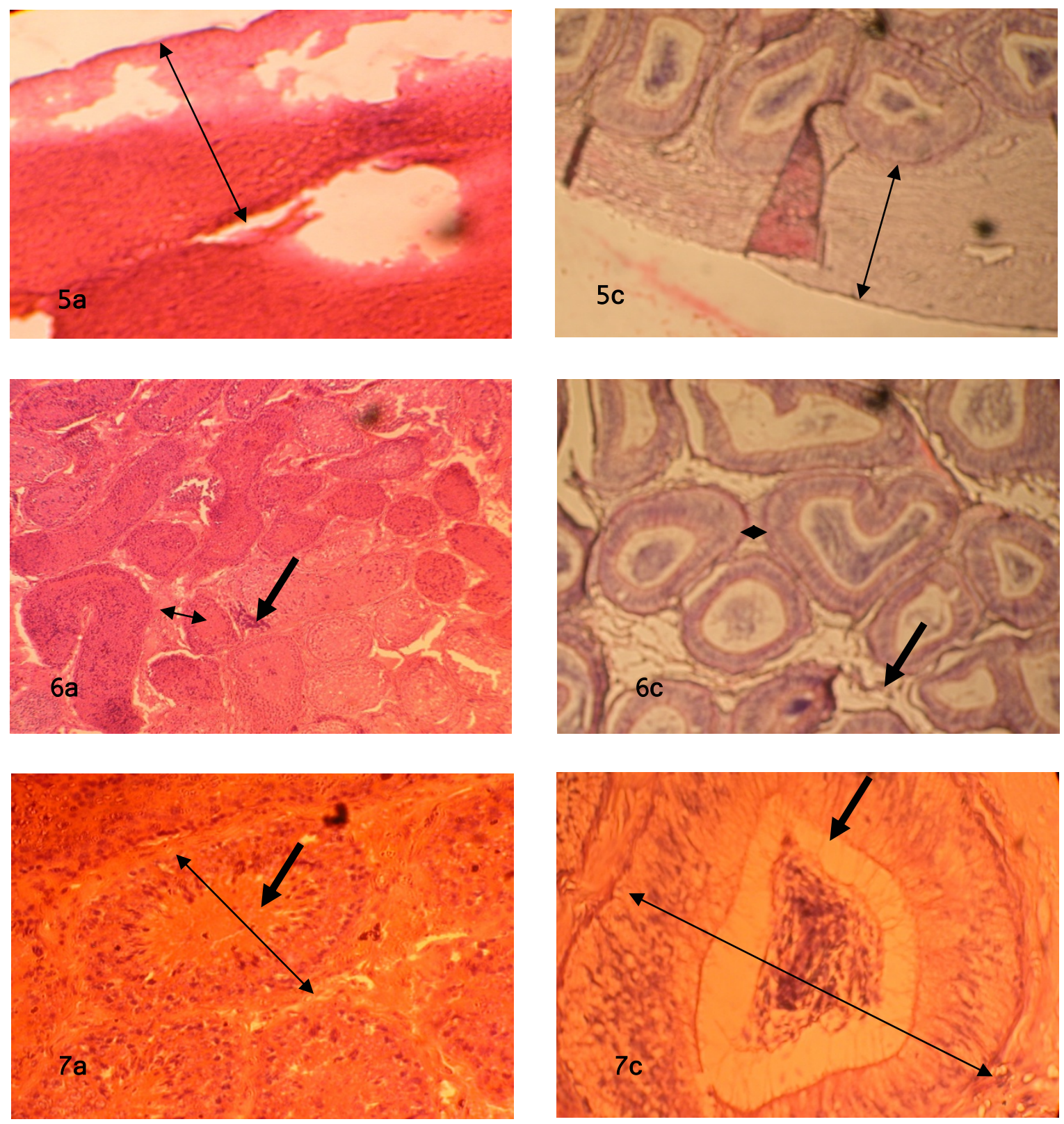

Fig. 5, 6, 7. Comparison of histological effects of arsenic on epididymis in affected goats (left side) and control group (right side). Arsenic affected goats showing, increased thickness of covering (single arrow, 5a), increased thickness of trabeculae (single arrow, 6a), increased thickness of interlobular space (double arrow, 6a) of epididymis compared to control group of goats (5c and 6c). Fig. 7a showing decreased diameter of ductuli efferentes (narrow single arrow) and decreased spermatozoa in the lumen of ductuli efferentes (thick single arrow) of the arsenic affected goats compared to control group of goats (7c). H \& E x100 (5a, 5c, 6a and 6c) and $\mathrm{H} \& \mathrm{E} \times 1000(7 \mathrm{a}$ and $7 \mathrm{c})$ 

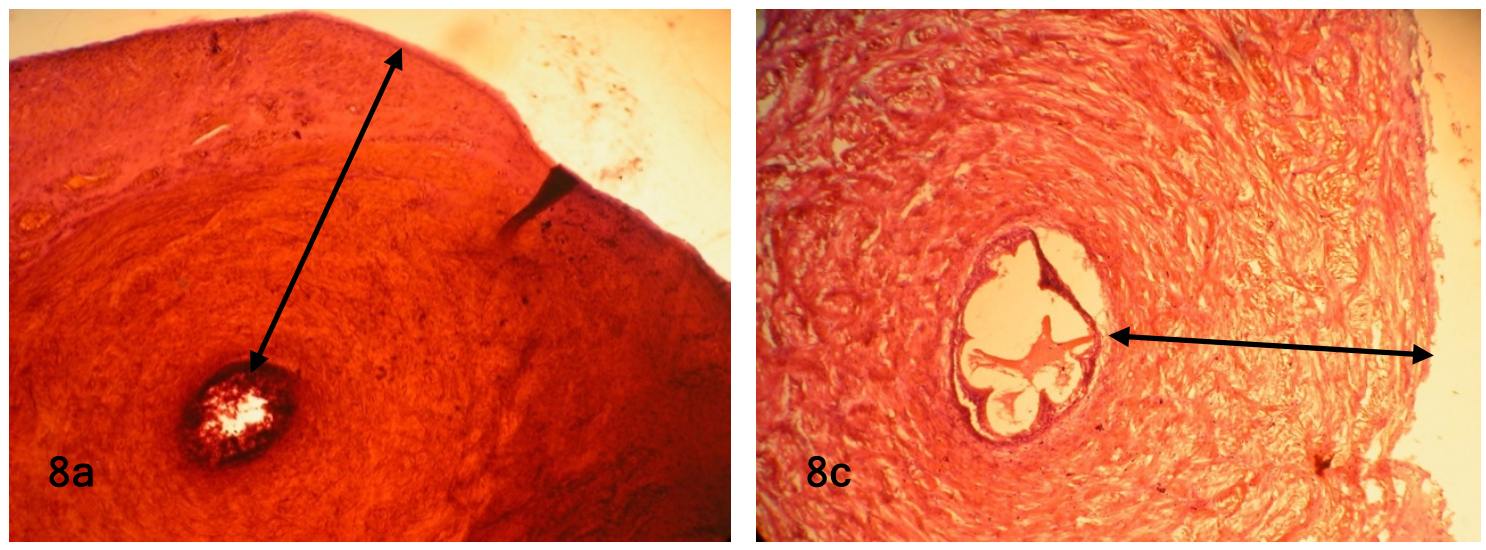

Fig. 8. Comparison of histological effects of arsenic on ductus deferens, showing significant thickening of wall of ductus deferens in arsenic affected goats (8a) compared to control group of goats (8c), single arrow. H \& E X 200

\section{Conclusions}

It is suggested that environmental health hazard of arsenic adversely affects the male reproductive organs (epididymis and ductus deferens) of Black Bengal goats, causing infertility.

\section{References}

Awal, M.A. 2007. Detection of arsenic in the food chains and animal samples and study of the preventive measure using the best cost-effective agricultural products based spirulin against arseniasis in man and livestock. Annual Research Report (20062007), USDA- Bangladesh collaborative research.

Bangladesh Arsenic Mitigation Water Supply Project (BAMWSP). 2001. Status Report of Bangladesh Arsenic Mitigation Water Supply Project, December, 2001.

Department of Public Health Engneering (DPHE), British Geological Survey (BGS) and Mott MacDonald Ltd (MML). 1999. Groundwater studies for arsenic contamination in Bangladesh, Final Report, Phase-I, January. EAWAG-SANDEC, 1998, SODIS News. No.3.

Fujihara, J. Kunito, Kubota, T., R. Tanaka H. and Tanabe, S. 2004. Arsenic accumulation and distribution in tissues of black-footed albatrosses. Marine-Pollution-Bulletin. 2004; 48(11/12): 1153-1160

Goebl, H.H., Schmidt, P.F., Bohl, J., Teltenborn B, Kramer G and Gutmann, L 1990. Polyneuropathy due to arsenic intoxication: biopsy studies. Journal of Neurology. 49: 137-149.

Gridley, M.F. 1960. Manual of Histologic and Special Staining Technique. McGraw-Hill Book Company, New York, NY. pp. 28-29 and 82-83.

Longnecker, M.P. and Daniels, J.L. 2001. Environmental contaminants as etiologic factors for diabetes. Environmental Health Perspectives. 6: 871-876. Lin-ChaiChing, Huang-

Mahmood, S.A.I. 2002. Arsenic is the silent killer. The Bangladesh Observer, 9th May, 2002.

Mazumder, D.N.G. 2008. Chronic arsenic toxicity \& human health. Indian Journal of Medical Research. 128: 436-47.

Islam, M.T., Parvin, S., Pervin, M., Bari2, A.S.M. and Khan, M.A.H.N.A. 2011. Effects of chronic arsenic toxicity on the hematology and histoarchitecture of female reproductive system of black Bengal goat. Bangl. J. Vet. Med. (2011). 9(1): 59 - 66

Mahitosh-Sarkar, Chaudhuri, G.R. Aloke-Chattopadhyay and Biswas, N.M. 2003. Effect of sodium arsenite on spermatogenesis, plasma gonadotrophins and testosterone in rats. Asian-Journal-of-Andrology. 2003; 5(1): 27-31

Neiger, R.D. and Osweiler, G.D. 1989. Effect of subacute low level dietary sodium arsenite on dogs.Fundamental and Applied Toxicology. 13: 439-451.

Sarkar, M., Biswas, N.M. and Ghosh, D. 1991. Effect of sodium arsenite on testicular 5-3,17-HSD activities in albino rats: Dose and duration dependent responses. Medical Science and Research. 19: 789-790.

Smith, A..H., Lingas, E.O. and Rahman, M. 2000. Contamination of drinking-water by arsenic in Bangladesh: A public health emergency. Bull WHO, 78: 1093-1103. 
Sukla, J.P. and Pandey, K. 1984. Impaired spermatogenesis in arsenic-treated fresh water fish Colisa fasciatus (BI \& Sch). Toxicology Letters. 21: 191-195.

Tseng, C.H., Tseng, C.P., Chiou, H.Y., Hsueh, Y.M., Chong, C.K. and Chen, C.J. 2002. Epidemiologic evidence of diabetogenic effect of arsenic. Toxicology Letters. 133: 69-76.

Ulman, C., Gezer, S., Anal, O., Tore, I.R. and Kirca, U. 2004. Arsenic in human and cow's milk: a reflection of environmental pollution. Water Air Soil Pollution. 101: 411-416.

Waalkes, M.P., Ward, J.M., Liu, J. and Diwan, B.A. 2003. Transplacental carcinogenicity of inorganic arsenic in the drinking water: induction of hepatic, ovarian, pulmonary, and adrenal tumors in mice. Toxicology and Applied Pharmacology. 186: 7-17.

Wahidur, R. 2006. Arsenic Exposure in Bangladesh: The Reproductive and Developmental Health Effects in Humans. Philadelphia Annual Meeting held on 22-25 October, 2006. Paper No. 67-73

WHO (World Health Organization). 2004. Water Sanitation and Health. Geneva, World Health Organization.

Yih, L. Peck K. and Lee, T. 2002. Changes in gene expression profiles of humanfibroblasts in response to sodium arsenite treatment. Carcinogenesis, 23: 867-876. 